\title{
LINGUAGEM, PODER E A COMPREENSÃO DO FENÔMENO JURÍDICO: APROXIMAÇÕES HERMENÊUTICAS COM A OBRA 1984 DE GEORGE ORWELL
}

\section{Leonel Pires Ohlweiler ${ }^{1}$ Ney Wiedemann Neto ${ }^{2}$}

\begin{abstract}
RESUMO: O texto examina a obra "1984", de George Orwell e a sua atualidade, com foco nas relações entre o Direito e a Linguagem, e as instâncias dogmáticas de poder que assumem nitidamente o papel do "Grande Irmão", suprimindo o Direito pelo controle da Linguagem.

Palavras-chave: 1984. George Orwell. Direito. Linguagem.

ABSTRACT: The article deals with the timeliness of the book "1984" by George Orwell, focusing on the relationship between Law and Language, and the dogmatic instances of power that clearly play the "Big Brother" role, suppressing the law trough the language control.
\end{abstract}

Keywords: 1984. George Orwell. Law. Language.

\section{Introdução}

Dialogar sobre as instigantes relações entre Direito e Literatura, na esteira das provocações de François Ost, não é uma explicação, mas uma hipótese interpretativa, isto é, múltiplas tentativas de relançar o pensamento num jogo de remissões sempre recomeçando. ${ }^{3}$ Tal afirmação é útil para o questionamento hermenêutico proposto nesse breve estudo, pois compreensão é construção de condições de possibilidades de sentido. Quais os efeitos quando instâncias de poder institucionalizadas pretendem eliminar este modo de ser do homem? Aliás, é possível tal desiderato? Não haveria uma eterna

\footnotetext{
1 Professor da disciplina de Teoria Geral do Direito, da Faculdade Inedi, Cesuca; professor do UNILASSALE; doutor em Direito (Unisinos-RS); desembargador do Tribunal de Justiça do Rio Grande do Sul.

${ }^{2}$ Professor da disciplina de Argumentação Jurídica, da Faculdade Inedi, Cesuca; professor da Escola Superior da Magistratura da AJURIS, mestre em Poder Judiciário (FGV-RJ); desembargador do Tribunal de Justiça do Rio Grande do Sul.

${ }^{3}$ Contar a Lei. As Fontes do Imaginário Jurídico. São Leopoldo: Unisinos, 2004, p.386.
} 
condenação à prática de crimideia? Tais questionamentos integram as preocupações da pesquisa, de modo a lançar um olhar transgressor sobre a compreensão do fenômeno jurídico, a partir das relações entre Direito e Literatura.

Inicialmente será examinada esta aproximação, na linha de diversas publicações sobre o tema, pois o fenômeno jurídico possui a dimensão da linguagem. Dominar a linguagem, sequestrando do intérprete as possibilidades do tempo, do sentido, faz parte do projeto que institucionaliza o dogmatismo no âmbito do Direito. A obra 1984 de George Orwell, dentre diversas questões, coloca exatamente este processo de dominação, mas com o discurso institucionalizado de que o Grande Irmão zela por ti.

A abordagem destas múltiplas relações entre a linguagem da literatura e do Direito ocorre por meio de Hans-Georg Gadamer e Ronald Dworkin, pois ambos são preocupados com a interpretação, não sob o ponto de vista de construir uma metodologia, mas explicitando o modo como ocorre a compreensão.

Na segunda parte são destacados os aspectos mais significativos da obra que será analisada, sempre com a postura do diálogo. Cada leitura do texto relembra a metáfora de Ronald Dworkin quando aborda a chain of Law, ler 1984 é sempre uma experiência enriquecedora, um autêntico acontecimento hermenêutico.

Por fim, na medida em que a preocupação desta pesquisa é a relação entre Direito e Literatura, sob a perspectiva da linguagem, a grande metáfora do romance de Orwell é a Novilíngua.

\section{Direito e Literatura: condições de possibilidade para uma hipótese interpretativa.}

Ronald Dworkin ${ }^{4}$ refere que a prática jurídica seria um grande exercício de interpretação. Desta forma, é bastante criticável a posição segundo a qual o Direito é visto simplesmente como uma questão de fato. Vetustas concepções sugerindo ser suficiente dar o fato para ter o direito, merecem um olhar crítico, pois o direito não surge de fatos propriamente ditos, mas de narrativas. Não é por outra razão que um dos efeitos perversos das dogmatizações, como aquela realizada pelo Grande Irmão, tem vocação para controlar a linguagem, exercendo-se papel crucial para restringir a significação das narrativas. 
Como recorda François Ost é da narrativa que sai o Direito:

"tudo se passa como se, entre toda a gama dos roteiros que a ficção imagina, a sociedade selecionasse uma intriga tipo que ela normatiza a seguir sob a forma de regra imperativa acompanhada de sanções"5.

Corolário, a compreensão é fundamental para a construção de narrativas jurídicas, elemento este que aproxima consideravelmente o Direito da Literatura. Estabelecer tal aproximação é um desafio, e adotando a perspectiva de François Ost para quem a literatura é capaz de desempenar uma função de subversão crítica ${ }^{6}$.

Mergulhar na obra "1984" possibilita dialogar com o modo de ser dos processos da dogmática jurídica, relacionados com a interpretação e de como é importante a vigilância hermenêutica para não cair no horizonte de sentido do senso comum, das narrativas arbitrariamente impostas.

Compreender é muito mais do que a simplista explicação de ter acesso a textos e fatos, eis que não há como divorciar a compreensão da experiência humana de encontrar-se diante da totalidade do mundo. Não é por outra razão que Hans-Georg Gadamer, em sua obra Verdade e Método, volta-se para o problema de como acontece a compreensão e quais as suas condições de possibilidade. No livro de Orwell é nítida a estratégia utilizada para o processo de dominação: fragmentar o sentido de mundo da comunidade, alterando a tradição, distanciando-a da experiência. A linguagem exerce papel crucial, pois a redução dos significados é utilizada com nítidos fins da ideologia do Partido.

O olhar aqui proposto pretende distanciar-se de uma posição meramente estética ou histórica do fenômeno jurídico e da literatura, direcionando-se para indagações de cunho mais ontológico, de construção de sentido e de como as relações com o poder estão presentes neste tema. Os estudos sobre literatura são profícuos, considerando a vasta experiência no exame de textos como construções de sentido e muitas vezes primando pela abordagem interdisciplinar.

O jurídico, desta forma, está ligado com a compreensão, razão pela qual Ronald Dworkin vai afirmar que o Direito é um fenômeno social, mas em razão de sua

\footnotetext{
${ }^{4}$ O Império do Direito. São Paulo: Martins Fontes, 1999, p. 17.

${ }^{5}$ Contar a Lei. As Fontes do Imaginário Jurídico. São Leopoldo: Unisinos, 2004, p. 24.

${ }^{6}$, Contar a Lei. As Fontes do Imaginário Jurídico p. 25.
} 
complexidade possui na sua estrutura a prática argumentativa ${ }^{7}$. Conforme será explicitado, é importante destacar o caráter argumentativo do direito, mas o que não é dado é apostar todas as fichas em tal afirmação, até porque somente se argumenta quando previamente houve a compreensão. A hermenêutica filosófica de Hans-Georg Gadamer é crucial para bem visualizar este problema. Segundo este filósofo, a compreensão engloba toda a experiência e autoconsciência que é capaz de assumir o existente humano. Aqui se destacam a abertura para o mundo e a finitude. Gadamer, ao construir sua teorização hermenêutica, funda-se em alguns elementos importantes do pensamento de Martin Heidegger. Este último, procurando fugir de concepções psicologistas, centra sua atenção no modo de ser do Dasein, existência humana, responsável por toda a compreensão do Ser. Compreender, portanto, depende do modo como o homem está no mundo. No âmbito desta abertura é que surgem as condições de possibilidade do sentido ${ }^{8}$.

A interpretação literária, neste ponto, é muito interessante quando destaca a importância do contexto ${ }^{9}$ no processo de interpretação. Interpretar algo, no caso, textos, não reside em simplesmente resgatar uma eventual intenção do seu autor. Ronald Dworkin, quando responde a indagação relativamente à intenção do autor na interpretação artística, refere:

\footnotetext{
“a interpretação artística não é simplesmente uma questão de recuperar a intenção de um autor se por 'intenção' entendermos um estado mental consciente, e não se atribuirmos à afirmação o significado de que a interpretação artística sempre pretende identificar um pensamento consciente específico que coordenava toda a orquestração na mente do autor quando este disse, escreveu ou criou sua obra. A intenção é sempre mais complexa e problemática"10.
}

\footnotetext{
${ }^{7}$ O Império do Direito. São Paulo: Martins Fontes, 1999, p. 17.

${ }^{8}$ Ver Ser e Tempo, Parte I, $5^{\text {a }}$ ed. Petrópolis, Vozes, 1995.

9 Como refere SILVA, Vitor Manuel de Aguiar e. Teoria da Literatura. $8^{\mathrm{a}}$ ed. Coimbra: Livraria Almedina, 2006, p. 296, a dimensão contextual do texto "atinente às relações externas(semânticoextensionais, pragmáticas, etc.) do texto, representa a abertura do texto literário à historicidade do homem, da sociedade e do mundo, quer no momento da sua produção, quer no momento - que são múltiplos e diversos momentos - da sua recepção".

${ }^{10}$ O Império do Direito. São Paulo: Martins Fontes, 1999, p. 67. Em outra passagem, refere o autor: "Quero dizer que uma interpretação é, por natureza, o relato de um propósito; ela propõe uma forma de ver o que é interpretado - uma prática social ou uma tradição, tanto quanto um texto ou uma pintura como se este fosse o produto de uma decisão de perseguir um conjunto de temas, visões ou objetivos, uma direção em vez de outra. Essa estrutura é necessária a uma interpretação mesmo quando o material a ser interpretado é uma prática social, mesmo quando não existe nenhum ator real cuja mente possa ser investigada"(p. 71).
} 
O que acima foi referido decorre da concepção aqui adotada segundo a qual a compreensão jurídica não ocorre sobre coisas projetadas como dadas, mas configura-se a partir das condições do homem enquanto ente compreendedor.

As possibilidades da compreensão, desta feita, não estão relacionadas com aspectos da subjetividade ou do resgate da vontade mitológica do autor, mas dos modos de ser no mundo do intérprete. A interpretação é, portanto, este aclaramento, este desdobramento das possibilidades existenciais do homem. Como refere Antonio Osuna Fernández-Largo a interpretação não é mais que o desenvolvimento das possibilidades projetadas no compreender ${ }^{11}$. Não há um compreender ao qual se chega por um procedimento interpretativo, porque a interpretação explicita todas as possibilidades abertas pelo Dasein.

Assim, Ronald Dworkin afirma que as proposições de Direito não são meras descrições da história jurídica de maneira inequívoca, nem simplesmente valorativas, em algum modo, dissociada da história jurídica. São interpretativas da história jurídica, que combina elementos tanto da descrição quanto da valoração ${ }^{12}$. Ora, caso houvesse um procedimento capaz de "dar o sentido", a interpretação seria sempre inequívoca. Destarte, seria mera descrição de um passado, agora resgatado na decisão do presente.

A interpretação é que faz surgir o sentido, entendendo-se o sentido como aquilo no qual se apóia a compreensibilidade de algo. Logo, a partir de um olhar hermenêutico, não é crível crer que o sentido esteja flutuando sobre as coisas, bem como esteja fechado nelas tal qual como tesouro escondido ${ }^{13}$. Somente tem-se sentido quando o Dasein no âmbito de sua abertura ao mundo ocupa-se com os entes que descobre e os engloba em seu projeto. Interpretar decorre daquilo que é aberto como possibilidade de ser no mundo, pois compreender é uma manifestação ôntica do existente ${ }^{14}$.

\footnotetext{
11 La hermenêutica jurídica de Hans-Georg Gadamer. Valladolid: Secretariado de Publicaciones, Universidad, D.L., 1992, p. 44.

${ }^{12}$ Uma Questão de Princípio. São Paulo: Martins Fontes, 2000, p. 219.

${ }^{13}$ Cf. FERNÁNDEZ-LARGO, António Osuna. , La hermenêutica jurídica de Hans-Georg Gadamer p. 45.

${ }^{14}$ Cf. FERNÁNDEZ-LARGO, António Osuna. La hermenêutica jurídica de Hans-Georg Gadamer, p. 49. Sobre a questão ver HEIDEGGER, Martin. Ser e Tempo. Parte I, $5^{\text {a }}$ ed. Petrópolis: Vozes, 1995, p. 40, quando o filósofo refere que o Dasein possui um primado múltiplo frente a todos os outros entes. O primeiro é um primado ôntico, pois o Dasein é um ente determinado em seu ser pela existência. O segundo é um primado ontológico, com base em sua determinação da existência, o Dasein é em si mesmo ontológico. Pertence a este ente compreendedor uma compreensão do ser de todos os entes que não possuem o modo de ser do Dasein. Com efeito, deve ser o primeiro ente a ser interrogado, antes de qualquer outro.
} 
Outro aspecto a ser ressaltado reside no caráter histórico do compreender, funcionando a historicidade como mediação indissociável do processo de compreensão. Tal giro filosófico aparece na obra de Hans-Georg Gadamer quando destaca a importância de ultrapassar a busca do sentido nas vivências psíquicas do sujeito para o sentido atualizador dos textos do passado. De certo modo, Ronald Dworkin busca tal desiderato quando, ao retratar o Direito como interpretação, destaca as proximidades com a literatura, na famosa Chain Novel ${ }^{15}$.

É certo que esta dimensão histórica da compreensão elaborada por Hans-Georg Gadamer não traduz em sua filosofia os pressupostos da Escola Histórica, até porque esta última ficou presa à razão como elemento determinante ${ }^{16}$. Em Gadamer a historicidade aparece como atualização presente de uma tradição, marcada pelo diálogo. Ora, é exatamente isto que faz o intérprete de um texto jurídico. Ao deparar-se com uma tradição de sentido não pode dar às costas para tal, mas assumir-se como responsável por continuar contando esta história, este conjunto narrativo.

Não se trata, portanto, de simplesmente transportar uma espécie de "razão histórica" para o presente, mas fazer acontecer as experiências narrativas do passado na atualidade e no horizonte de sentido do caso. Aqui é crucial a questão relativa à "fusão de horizontes" ${ }^{\prime 17}$, partindo-se do pressuposto segundo o qual o horizonte é um âmbito de visão que é dado desde um ponto determinado da história.

O projetar um horizonte histórico é um passo no trabalho da compreensão, crucial para abrir-se um novo horizonte no presente. Logo, “A compreensão vem a ser como um ultrapassar o limitado horizonte histórico e ganhar um novo horizonte

\footnotetext{
${ }^{15}$ Uma Questão de Princípio. São Paulo: Martins Fontes, 2000, p. 235. No âmbito do Direito, assim menciona Dworkin: "Suponha que um grupo de romancistas seja contratado para um determinado projeto e que jogue dados para definir a ordem do jogo. O de número mais baixo escreve o capítulo de abertura de um romance, que ele depois manda para o número seguinte, o qual acrescenta um capítulo, com a compreensão de que está acrescentando um capítulo a esse romance, não começando outro, e, depois, manda os dois capitulos para o número seguinte, e assim por diante. Ora, cada romancista, a não ser o primeiro, tem a dupla responsabilidade de interpretar e criar, pois precisa ler tudo o que foi feito antes para estabelecer, no sentido interpretativista, o que é o romance criado até então".

${ }^{16}$ Cf. FERNÁNDEZ-LARGO, António Osuna. La hermenêutica jurídica de Hans-Georg Gadamer, p. 54.

${ }^{17}$ Cf. GADAMER, Hans-Georg. Verdad y Método. Fundamentos de una hermenêutica filosófica. $5^{\mathrm{a}}$ ed. Salamanca: Ediciones Sígueme, 1993, p. 331 e seguintes. De forma explícita refere o autor: "en realización de la comprensión tiene lugar una verdadera fusión horizóntica que con el proyecto del horizonte histórico leva a cabo simultáneamente su superación”, p. 377.
} 
superador (fusão)" ${ }^{\prime 18}$. Os horizontes não se criam à margem do contraste com o passado, mas são frutos dialéticos do enfrentar-se desde o presente com o passado. A historicidade que aparece no processo de compreensão, desta forma, não se constitui em uma atividade simples de reviver algo que já aconteceu, mas em tornar presente o passado, de modo que a interpretação resulte do diálogo hermenêutico com o texto.

Em relação a este aspecto, também é interessante fazer uma aproximação com os estudos literários, pois, como bem refere Vitor Manuel de Aguiar e Silva, a literatura não consiste apenas numa herança, um conjunto cerrado e estático de textos, mas apresenta-se como um ininterrupto processo histórico de produção de novos textos, sendo que tais textos novos podem provocar modificações profundas nos textos até então produzidos, na medida em que propiciam ou determinam novas leituras desses mesmos textos ${ }^{19}$.

A prática jurídica, o labor do intérprete, sob tal perspectiva, é um contínuo processo de produzir novos textos e que propiciam novas leituras de textos anteriores. A literatura, com efeito, é um conjunto ou soma de obras ou textos literários. Ronald Dworkin examina este aspecto quando discorre que muito embora existam divergências no campo da teoria literária ao que é literatura, sentido e texto, os estudos literários procuram trabalhar a interpretação como o processo de compreensão voltado para a obtenção "da melhor obra literária" 20 . Muito embora a obra literária proporcione variadas leituras, "não permite leituras em número ilimitado ou de natureza

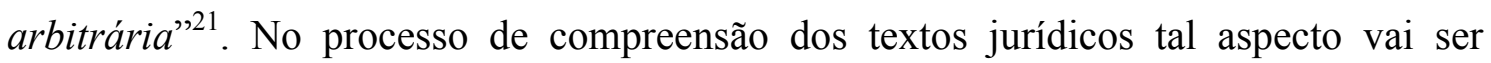
relevante, pois se desloca a questão do sentido jurídico das estruturas formais e dogmáticas, como discricionariedade e vinculação, para o processo de compreensão mesmo.

No entanto, assim como é possível laborar com uma diversidade de interpretações, não há como aceitar a possibilidade irrestrita de construção de sentidos ou a arbitrariedade do intérprete. Tais debates, que dominaram durante muito tempo os estudos literários, de algum modo, são profícuos para o Direito, até porque a

\footnotetext{
${ }^{18}$ Cf. FERNÁNDZ-LARGO, António Osuna. La hermenêutica jurídica de Hans-Georg Gadamer, p. 55. Ver ainda STRECK, Lenio Luiz. Hermenêutica Jurídica(e)m Crise. Uma exploração hermenêutica do Direito. $5^{\mathrm{a}}$ ed. Porto Alegre: Livraria do Advogado Editora.

${ }^{19}$ Op. cit., p. 14.

${ }^{20}$ Uma Questão de Princípio, p. 222.

${ }^{21}$ Cf. SILVA, Vitor Manuel de Aguiar e. Op. cit., p. 35.
} 
interpretação pode ser compreendida como uma obra, não como algo pronto e acabado, mas, nas palavras de Vitor Manuel de Aguiar e Silva, uma obra literária, ou seja:

\begin{abstract}
“como o próprio lexema 'obra' denota, constitui o resultado de um fazer, de um produzir, que sendo embora também um processo de expressão, é necessária e primordialmente um processo de significação e de comunicação ${ }^{22}$ ".
\end{abstract}

\title{
3. A Narrativa Literária da Obra 1984, de George Orwell.
}

A obra 1984 foi publicada em 1949, quando aquele ano parecia distante. Foi o último romance de George Orwell, poucos meses antes da sua morte. Eric Arthur Blair, que escrevia sob aquele pseudônimo, nasceu na Índia, em 1903, falecendo em 1950, de tuberculose. O livro relata uma história que se passa no "futuro" ano de 1984, na Inglaterra. A transformação da realidade é o tema principal desta obra. Passados muitos episódios históricos com os quais esse romance parece ter relação, como as ditaduras nazifascistas europeias ou o comunismo soviético, a obra permanece atual como reflexão sobre o absurdo do totalitarismo. Orwell teve a experiência de lutar na guerra civil espanhola, ao lado dos marxistas, que depois foram perseguidos pelo Stalinismo. A respeito da sua motivação para escrever esta obra, ele próprio comentou, em carta escrita sete meses antes de falecer:

\footnotetext{
"Meu romance recente [Nineteen Eighty-Four] NÃO foi concebido como um ataque ao socialismo ou ao Partido Trabalhista Britânico (do qual sou um entusiasta), mas como uma mostra das perversões... que já foram parcialmente realizadas pelo comunismo e fascismo. O cenário do livro é definido na Grã-Bretanha a fim de enfatizar que as raças que falam inglês não são intrinsecamente melhor do que nenhuma outra e que o totalitarismo, se não for combatido, pode triunfar em qualquer lugar." (IN Collected Essays The Collected Essays, Journalism and Letters of George Orwell Volume 4 - In Front of Your Nose $1945-1950$ p.546 Penguin). ${ }^{23}$
}

\footnotetext{
${ }^{22}$ Teoria da Literatura. $8^{\text {a }}$ ed. Almedina: Coimbra, 2006, p. 75.
} 
A história se passa em Oceania, um bloco formado pelas Américas, Inglaterra, Sul da África e Austrália. Os outros blocos em que se dividia o mundo eram a Lestásia e a Eurásia. Em Oceania havia um idioma oficial, chamado de "Novafala" ou de "Novilíngua". O novo idioma tinha o objetivo de reduzir a capacidade de pensamento das pessoas. Sob a perspectiva aqui adotada, uma forma de controle do modo de ser no mundo!

A personagem central, Winston Smith, sente-se refém de um mundo opressor. Oceania é um lugar onde não há espaço para mentes livres. Todos são controlados pelo "Grande Irmão", líder simbólico do Partido. Numa sociedade dominada pelo Estado, tudo é feito coletivamente, mas as pessoas vivem isoladas umas das outras.

Intimamente, Winston se rebela contra esse totalitarismo, na busca por liberdade e por verdade, envolvendo-se amorosamente com uma colega de trabalho e com uma organização revolucionária. Os que infringiam as regras do Partido eram capturados pela Polícia do Pensamento, desaparecendo. Winston o tempo inteiro tenta fugir do sistema, transgredir, se esconde para escrever, se envolve com quem não podia.

Orwell usa correlação de nomes das instituições para simbolizar o oposto do que elas representavam. Winston trabalhava no Ministério da Verdade, em tese responsável por notícias, entretenimento, educação e belas-artes. A função dele, porém, era a de reescrever e alterar dados de acordo com o interesse do Partido, até mesmo a mutabilidade do passado, mecanismo criado para apagar da memória das pessoas o que convinha ao "Grande Irmão".

Por isso, os três slogans do Partido, em vários locais divulgados, também eram paradoxais: GUERRA É PAZ. LIBERDADE É ESCRAVIDÃO. IGNORÂNCIA É FORÇA. Nesse contexto, vale a máxima: "Quem controla o passado, controla o presente, e quem controla o presente, controla o futuro". Ao reescrever o passado, e mantendo o povo em estado de ignorância, maior era o poder de controle e a opressão do Estado, mais forte ele era.

Chama a atenção, no início da obra, que Winston começa a escrever um diário, com a certeza de que, se fosse descoberto pelo "Grande Irmão", sua punição seria a morte ou pelo menos vinte e cinco anos de prisão em campo de trabalhos forçados. “Não que isso fosse ilegal (nada era ilegal, visto que já não existiam leis)”. Se alguém

\footnotetext{
23 Nineteen Eighty-Four. Wikipedia. Disponível em HTTP:PT.wikipedia.org/wiki/Nineteen Eighty-
} Four\#cite note-12.Acesso em 19 nov.2012. 
pensasse diferente, cometia "crimideia" (crime de ideia em "novilíngua") e fatalmente seria capturado pela Polícia do Pensamento e era "vaporizado" (desaparecia). Naquela sociedade não havia direito, sobretudo penal, pois não havia crimes.

Winston representa o cidadão comum vigiado pelas teletelas e pelas diretrizes do Partido. Ele e todos os cidadãos sabiam que qualquer atitude suspeita poderia significar o fim. No Estado totalitário, é aterrorizante a não existência do Princípio da Legalidade, porque o cidadão fica refém da discricionariedade e do arbítrio dos hierarcas do Partido, que não necessitam dos demonstrar que os limites da lei foram transgredidos, já que elas não existem, para eliminar aqueles que vêem como uma ameaça.

A obra é fundamental para compreender os dias atuais e o próprio fenômeno jurídico, especialmente acerca de quem tenta controlar nossa sociedade, bem como os processos de compreensão. Winston filtrava o que chegava ao ouvido da população, era a informação que desinformava.

A proposta desta pesquisa é refletir sobre as condições de possibilidade de pensar o modo de ser do Direito, relacionando-o com a linguagem e as instâncias dogmáticas de poder que assumem nitidamente o papel do "Grande Irmão". A "Novilingua", em última análise destina-se à controlar a capacidade narrativa da comunidade, além de cada vez mais arbitrariamente alterar o sentido da tradição, isolando o homem de sua própria história.

\section{A Novilingua com Locus Metafísico: aportes para a compreensão crítica do}

\section{fenômeno jurídico.}

Conforme já explicitado, a linguagem ocupa papel central na concepção hermenêutica de Hans-Georg Gadamer, eis que o processo hermenêutico é essencialmente linguístico, concebendo-se a linguagem como "el meio en que se realiza el acuerdo de los interlocutores y el consenso sobre la cosa" ${ }^{\text {24 }}$. Para o Direito tal aspecto é fundamental. Uma das razões pelas quais ainda hoje impera o dogmatismo na prática cotidiana dos operadores decorre do modo como se relacionam com a linguagem

\footnotetext{
${ }^{24}$ Verdad y Método. I, p. 462. Deixar de ser pensada como instrumento, significa que a linguagem passa a ter um caráter constitutivo, quer dizer, o homem não tem acesso direto aos entes do mundo, mas somente com e na linguagem. Esta não funciona como um algo que primeiro estabelece as características objetivas de uma coisa e, após, está apta para ser captada pelo intérprete. O ato compreendedor já se dá na
} 
jurídica. Na obra de Orwell detecta-se o papel desempenhado pela "Novilíngua", pois construída para impossibilitar o pensamento. Vale referir parte de um dos instigantes diálogos entre Syme e Winston ${ }^{25}$ :

\footnotetext{
"-Não vês que todo o objetivo da Novilíngua é estreitar a gama do pensamento. No fim tornaremos a crimideia literalmente impossível, porque não haverá palavras para expressá-la. Todos os conceitos necessários serão expressos exatamente por uma palavra, de sentido rigidamente definido, e cada significado subsidiário eliminado, esquecido."
}

Esta passagem é significativa e elucida que um dos modos de dominar o processo de compreensão, inclusive o jurídico, é uniformizando a linguagem, a tal ponto de construir espaços absolutos de sentido. Daí as desconfianças com objetivos similares de construção de "uma linguagem rigorosa" para a compreensão dos fenômenos jurídicos. É claro que com isto não se trata de cair no vazio do relativismo, até porque a ausência de segurança jurídica também se constitui em outra instância do poder para os processos de dominação. Não se pode olvidar que na Oceania do livro 1984 sequer havia lei. Trata-se, assim, de questão importante para refletir: as relações entre liberdade na produção de sentido e segurança jurídica. A grande crítica do texto literário de Orwell consiste que a dominação não precisa de leis, aliás, para a institucionalização do arbítrio, é melhor que nem existam, pois controlando a linguagem e o pensamento dos cidadãos, domina-se o próprio modo de ser do homem.

No campo jurídico sempre é importante fazer a distinção entre dogmática e dogmatismo. A primeira está relacionada com uma das formas de construção do conhecimento jurídico, laborando com o que se poderia nominar de indícios formais, enquanto o dogmatismo constitui-se na tentativa de isolar o jurídico do mundo prático, despreocupando-se das diversas formas de existência, erigindo um conhecimento formal $^{26}$, dotado de caráter metafísico. A metafísica revela-se como forma de

linguagem, possibilitando o conhecimento dos fenômenos que nos cercam. Por esta razão, Gadamer vai dizer que o homem participa na linguagem.

${ }^{25}$ ORWELL, George. 1984, p. 54.

${ }^{26}$ Sobre o tema ver OHLWEILER, Leonel. Direito Administrativo em Perspectiva. Os Termos Indeterminados à Luz da Hermenêutica. Livraria do Advogado: Porto Alegre, 2000, p. 45 e Teoria Versus Prática: em busca da função social da dogmática jurídica (o exemplo privilegiado do Direito Administrativo), In: Revista do Instituto de Hermenêutica Jurídica. Vol. 1, n. 3, IHJ: Porto Alegre, 2005, p. 129-164. 
compreender o sentido dos entes jurídicos, mas de forma objetificada, caracterizando-se pelas idéias de (a)fundamento último e (b)compreensão auto-referencial ${ }^{27}$.

A concepção de George Orwell sobre poder e dominação está repleta destas características, pois é possível dizer que o fundamento último dos entes está naquilo que diz o "Grande Irmão". Tudo que se podia dizer e pensar na Oceania origina-se da linguagem construída pelo Partido. É interessante como estes mecanismos de dominação funcionavam, possibilitando diversas reflexões sobre o modo de limitação de sentido do dogmatismo jurídico. Por vezes tem-se a impressão de que também há uma espécie "Grande Irmão Jurídico", ao qual se atribui as únicas condições de possibilidade do conhecimento. Mas não basta erigir um fundamento único, de caráter metafísico, é preciso também controlar o modo de compreender. Na obra em exame, surge a Polícia do Pensamento, desdobramento material da força do Partido para controlar. Aspecto interessante reside na dimensão simbólica exercida sobre o cidadão, pois nunca se sabe quando a Polícia do Pensamento atacará:

\begin{abstract}
"Naturalmente, não havia jeito de determinar-se, num dado momento, o cidadão estava sendo vigiado ou não. Impossível saber com que frequência, ou que periodicidade a Polícia do Pensamento ligava para a casa deste ou daquele indivíduo."28
\end{abstract}

A manipulação arbitrária da linguagem também é desdobramento desta postura de dogmatismo, de uma espécie de totalitarismo de sentido, ao ponto de haver um completo divórcio entre o sentido de base das palavras e o significado, induzindo os cidadãos a aceitarem esta linguagem. A título de exemplo as funções do governo na Oceania eram exercidas pelo Ministério da Verdade, que se ocupava da construção de mentiras, da falsificação do passado, o Ministério da Paz, que se ocupava da guerra,

\footnotetext{
${ }^{27}$ Cf. MICHELAZZO, José. Do Um como Principio ao Dois como Unidade: Heidegger e a reconstrução ontológica do real. São Paulo: FAPESP: Annablume, 1996, p. 41. Por meio da concepção de fundamento último, a compreensão é calcada em um determinado ponto de partida que não comporta nada que esteja além dele. Já, com relação à compreensão auto-referencial, somente mostra-se como um conhecimento válido, legítimo, aquele produzido desde os seus próprios enunciados, a partir dos quais é possível determinar a verdades dos entes em sua exatidão. Não deixa de ser uma clara representação do mito da caverna, pois há uma compreensão que se encontra "no fundo da caverna", portanto, obscura, devendo caminhar para o lado, o mundo das idéias, a fim de que possa realmente atingir aquilo que se deve compreender. No fundo da caverna há apenas sombras e no lado externo estão os entes jurídicos propriamente ditos, sendo imprescindível percorrer o caminho para poder atingir este "verdadeiro mundo". No pensamento da dogmática de cunho metafísico, o seu ponto fundante representa a direção a ser seguida para atingir-se o único conhecimento possível.
} 
pelo Ministério do Amor, responsável por manter a lei e a ordem e o Ministério da Fartura, que acudia às atividades econômicas ${ }^{29}$.

Não se pode esquecer que a compreensão de um texto ocorre na forma de uma conversação hermenêutica, na qual o intérprete participa do sentido do texto. Não é crível falar em compreender como atividade de mera reconstrução da gênese do texto, segundo Hans-Georg Gadamer ${ }^{30}$. Trata-se, com efeito, de uma fusão de horizontes, realizada na forma de conversação ocorrida no âmbito da linguagem, ou seja, conforme o filósofo, "la lenguaje es le medio universal en el que se realiza la comprensión misma. La forma de realización de la comprensión es la interpretación" ${ }^{31}$. Com isto, afirma-se o caráter constitutivo da linguagem relativamente ao próprio existir humano, não possuindo uma mera função de instrumento, quer dizer, uma estrutura prévia e que depois de reconstruída estaria apta para veicular o sentido das coisas. As coisas do mundo, poder-se-ia dizer, ocorrem no modo de ser linguagem.

No processo de dominação, como descrito por George Orwell, igualmente elimina-se a possibilidade de qualquer conversação, de diálogo. Para tal desiderato, inicialmente havia na Oceania a figura do Crimideia, impedindo que qualquer cidadão pensasse diferente das ideias construídas pelo Partido: “Crimideia não acarreta a morte: crimideia É a morte. ${ }^{32}$ " É interessante que no âmbito do conhecimento jurídico, por vezes, detecta-se uma espécie de "crimideia jurídico", ou seja, compreender diferente daquilo que é imposto pelo senso comum é um desvalor. É certo que no livro 1984, de fato, quem praticasse crimideia seria preso e "vaporizado", mas também a questão da morte possui um aspecto simbólico importante: a morte do sujeito. Quando não há qualquer possibilidade de diálogo, de participação nos processos de construção de sentido jurídico, estamos à beira da morte do sujeito.

Daí a necessidade de cada vez mais pensar em estratégias que aumentem a institucionalização de condutas dialógicas no campo jurídico, tomando o logos não como razão, mas linguagem. Devido ao caráter fundante da linguagem no pensamento

\footnotetext{
${ }^{28}$ Cf. ORWELL, George. 1984, p. 6.

${ }^{29}$ Cf. ORWELL, George. 1984, p. 8.

${ }^{30}$ Verdad y Método I, p. 466.

${ }^{31}$ GADAMER, Hans-Georg. Verdad y Método I, p. 467. Sobre esta questão indica ROHDEN, Luiz. Hermenêutica Filosófica. Entre a linguagem da experiência e a experiência da linguagem. São Leopoldo: EdUnisinos, 2002, p. 227: "Medium para o que Gadamer aqui se propõe, não deve ser compreendido como meio (Mittel) no sentido instrumental- no sentido de nomear, p. ex., para dominar -, mas como meio (Mitte) no sentido de lugar, espaço, meio-ambiente, circunstância, centro, modo de algo ser e realizar-se".
} 
hermenêutico de Hans-Georg Gadamer, o filósofo ressalta o equívoco do pensamento ocidental ao compreender a expressão "O homem é um ser dotado de logos" como o homem é um ser dotado de "razão", pois no seu entendimento "logos" significaria, sobretudo, "linguagem"33.

A tradição apresenta-se como fundamental no processo de compreensão, pois as coisas do mundo, os entes, chegam a partir de uma dada tradição. Este é mais um aspecto interessante que se desvela da obra de George Orwell. Qual a relação deste tema com a linguisticidade? Para Gadamer, um elemento primordial da tradição consiste em existir no meio da linguagem e a tradição linguística não é simplesmente uma relíquia a ser investigada, mas algo transmitido para o homem, assumindo especial importância a tradição escrita ${ }^{34}$.

Mergulhar na tradição, portanto, é muito mais do que um simples descobrir, mas participar do seu acontecer, naquilo que é dito pelo texto que chega do passado. Este aspecto é importante para detectar-se não haver, hermeneuticamente falando, uma relação direta entre o intérprete e o autor do texto, pois na medida em que as "coisas são linguisticamente" dadas por uma tradição é possível dizer haver não uma relação e sim uma participação naquilo que o texto comunica. Hans-Georg Gadamer refere que "la lectura comprensiva no es repetición de algo pasado, sino participación em um sentido presente" ${ }^{35}$. Desta forma, não havendo uma mera atividade de repetir um algo já dito, não se apresenta possível limitar o horizonte da interpretação àquilo que o autor do texto tinha em mente na sua origem, até porque "conceptos normativos como la opinión del autor o la comprensión del lector originario no representan en realidad más que una posición vacia que se satura sólo de ocasión en ocasión de comprender" ${ }^{36}$.

\footnotetext{
${ }^{32}$ Cf. ORWELL, George. 1984, p. 29.

${ }^{33}$ Cf. GADAMER, Hans-Georg. Hombre y lenguaje. In: Verdad y Método II, p. 145-52. Traduzido por Manuel Olasagasti. Salamanca: Sígueme, 1992 p. 145. O filósofo faz referência ao pensamento de Aristóteles quando este último fala da diferença entre o homem e o animal, aludindo que somente ao homem teria sido dado, além da capacidade de entender-se com outros, o logos para poder revelar um ao outro o que é útil e o que é prejudicial, e o que é justo e injusto. Igualmente, aduz expressamente sobre as consequências de o homem possuir "logos": "puede pensar y puede hablar. Puede hablar, es decir, hacer patente lo no actual mediante su lenguaje, de forma que también outro lo pueda ver. Puede comunicar todo lo que piensa; y lo que es más, gracias a esa capacidad de comunicarse las personas pueden pensar lo común, tener conceptos comunes, sobre todo aquellos conceptos que posibilitan la convivencia de los hombres sin asesinatos ni homicidios, en forma de vida social, de una constitución política, de una vida económica articulada en la división del trabajo. Todo esto va implícito en el simples enunciado de que el hombre es el ser vivo dotado de lenguaje" (Verdad y Método II,. 145) .

${ }^{34}$ GADAMER, Hans-Georg. Verdad y Método I, p. 468.

${ }^{35}$ GADAMER, Hans-Georg. Verdad y Método I, p. 471.

${ }^{36}$ Cf. GADAMER, Hans-Georg. Verdad y Método I, p. 475.
} 
Como já mencionado, na Oceania existia um órgão encarregado exatamente de alterar o passado, a tradição escrita que chega aos cidadãos. As palavras de Winston demonstram bem o dilema no qual o cidadão que não tem a possibilidade de diálogo com o passado encontra-se:

"La embaixo, na rua, o vento ainda fustigava o cartaz rasgado, e a palavra INGSOC ora aparecia ora desparecia. Ingsoc. Os princípios sagrados do Ingsoc. Novilíngua, duplipensar, a mutabilidade do passado. Sentiu-se como quem vagueia nas florestas do fundo do mar, perdido num mundo monstruoso onde ele próprio era o monstro. Estava só. O passado morto, o futuro inimaginável." ${ }^{37}$

A passagem mencionada é indicativa da importância da tradição e do passado, pois toda compreensão estrutura-se por meio da linguagem que o homem é enquanto logos. Fazer parte de uma linguagem é crucial para o verdadeiro acontecer, fundado hermeneuticamente naquilo que nos chega da tradição. Nas origens de um poder que dogmatiza a linguagem e a construção dos sentidos, está o isolamento em relação ao passado.

Para Hans-Georg Gadamer o conteúdo da tradição acontece como possibilidades de sentido que chegam ao intérprete e que a cada momento são ampliadas por aquele que as recebe, pois quando a tradição volta a falar emerge algo que é, desde então, e que antes não era, sendo relevante ouvir o que chega a partir da tradição, pois "la verdad de la tradición es como el presente que se abre inmediatamente a los sentido" ${ }^{38}$.

Em toda compreensão haveria uma comunicação linguística entre presente e tradição, responsável pelo acontecer hermenêutico, ou seja, a ação das coisas mesmas. Aqui reside uma questão primordial da Novilíngua: obstaculizar a ação das coisas

\footnotetext{
${ }^{37}$ Cf. ORWELL, George. 1984, p. 28.

${ }^{38}$ GADAMER, Hans-Georg. Verdad y Método I, p. 554. A circunstância de Gadamer ter atribuído à tradição um papel relevante no processo hermenêutica rendeu-lhe algumas críticas de ter instaurado um conservadorismo na compreensão. Ficou famoso o debate entre o filósofo e Jürgen Habermas. Sobre o tema ver HABERMAS, Juren. Dialítica e Hermenéutica: para a crítica da hermenéutica de Gadamer. Traduzido por Álvaro Vale. Porto Alegre: L \& PM, 1987. Para este último, a hermenêutica gadameriana não estaria apta para elaborar uma crítica e refletir sobre a dimensão ideológica presente em toda a linguagem, estando comprometida, assim, sua pretensão de universalidade. Destarte, a hermenêutica não seria capaz de ultrapassar a tradição, fazendo a distinção entre pré-juízos autênticos e pré-juízos inautênticos, cosiderando a ausência de uma dimensão crítica na construção teórica de Gadamer. No entanto, este filósofo defendeu o entendimento segundo o qual as preocupações levantadas por Habermas já estavam presentes em sua obra, pois, em última análise, tinha por objetivo fazer uma crítica à crença iluminista e ingênua no método. Outrossim, admitindo a importância da reflexão crítica, sustentou a sua presença na hermenêutica desenvolvida em Verdade e Método.
} 
mesmas, do autêntico acontecer hermenêutico. Sobre a alteração do passado, vale referir:

\begin{abstract}
"Todavia, a razão mais importante para o reajuste do passado é a necessidade de salvaguardar a infalibilidade do Partido. Não significa apenas que se modifiquem discursos, estatísticas e registros de todo gênero para demonstrar que as predições do Partido são sempre certas. É que não se pode admitir, jamais, nenhuma modificação de doutrina ou de agrupamento político. (...) Assim se reescreve continuamente a história. Essa falsificação cotidiana do passado, realizada pelo Ministério da Verdade é tão necessária à estabilidade do regime como o trabalho de representação e espionagem levado a cabo pelo Ministério do Amor.(...) A mutabilidade do passado é o dogma central do Ingsoc. Argúe-se que os acontecimentos passados não têm existência objetiva, porém só sobrevivem em registros escritos e as memórias. E como o partido tem pleno controle de todos os registros e igualmente do cérebro dos seus membros, segue-se que o passado é o que o Partido deseja que seja." ${ }^{~} 39$
\end{abstract}

Esta incursão na obra 1984 possibilita o olhar crítico sobre algumas formas corriqueiras de dizer o direito, como aquelas contidas nos manuais que isolam o operador do Direito da tradição, obviamente, não por meio da força, mas do simbólico contido na linguagem do senso comum. A tradição da qual nos fala Gadamer, como companheira de diálogo, possui um modo de ser objetivo, de algo que era desde então como refere o filósofo, não sendo crível aceitar a postura dogmática de alteração do próprio sentido, apenas para dotar de coerência o discurso do Partido.

Aqui se remonta à seguinte expressão: vigilância hermenêutica. A hermenêutica possui uma configuração especulativa, isto é, contrária à posição do dogmatismo, não se entregando direta e acriticamente ao conjunto de posições dominantes, destacando-se pelo seu aspecto de saber refletir, como alude Gadamer. Para ilustrar o caráter especulativo da linguagem, a poesia de Hölderlin é lançada em Verdade e Método no intuito de exemplificar o verdadeiro acontecer da poesia:

\footnotetext{
"Quando o poeta se sente captado em toda sua vida interna e externa pelo tom puro de sua sensibilidade originária e olha então a seu redor, para o seu mundo, este se lhe parece também novo e desconhecido; a soma de todas as suas experiências, de seu saber, de seu contemplar, de sua reflexão, arte e natureza, como se lhe
}

\footnotetext{
${ }^{39}$ Cf. ORWELL, George. 1984, p. 205.
} 
representam nele e fora dele, tudo aparece como se fora a primeira vez, sem conceitos, sem determinação, resultando em pura matéria e vida, presente. E é importantíssimo que neste momento não tome nada como dado, não parta de nada positivo, e que a natureza e a arte, tal como as têm aprendido antes e as ver agora, não fale antes que para ele exista uma linguagem (...)"40.

O texto supra citado é demonstrativo da concepção hermenêutica de Gadamer, pois a linguagem para o filósofo assemelha-se com a poesia no seu caráter especulativo, de criar o novo, o inédito, assumindo-se como instauradora de mundo. Não há na poesia um labor de reprodução de um algo previamente fixado e estabelecido, mas a representação do aspecto de um novo mundo. Na obra de George Orwell é interessante a referência que aparece sobre a poesia. No Setor de Registros havia uma figura sonhadora, ineficiente para os padrões do Partido, uma criatura terna chamada Ampleforth, colega de Winston, cuja função era modificar textos definitivos de poemas que se tornaram ideologicamente ofensivos, mas que tinham, por alguma razão, de ser conservados nas antologias ${ }^{41}$.

Quando Winston é preso, o poeta Ampleforth também é atirado dentro da cela, por um motivo que é significativo para indicar o caráter da linguagem poética: deixou que a palavra Deus ficasse no fim de um verso! Até o final, antes de ir para a Sala 101, o poeta permaneceu atrelado à sua posição: era impossível modificar o verso.

Trata-se, portanto, de outra metáfora para permitir a reflexão sobre o caráter originário da linguagem enquanto acontecimento. O processo de interpretação de um texto jurídico, igualmente, ocorre por meio de uma compreensão especulativa, possuindo "la estructura dialéctica de todo ser finito e histórico en cuanto que toda interpretación tiene que empezar por alguna parte e intentar superar la parcialidad que se introduce en ella con su comienzo" ${ }^{42}$.

\footnotetext{
${ }^{40}$ GADAMER, Hans-Georg. Verdad y Método I, p. 562-63. No entendimento de Gadamer a palavra na poesia é "más diciente", não havendo um ato de mera reprodução, cf. GADAMER, Hans-Georg. Acerca de la Verdad de la Palabra. In: Arte y Verdad de la Palabra. Traduzido por José Francisco Zúñiga Garcia e Faustino Oncina. Barcelona: Paidós, 1998, p. 30.

${ }^{41}$ Cf. ORWELL, George. 1984, p. 43.

${ }^{42}$ GADAMER, Hans-Georg. Verdad y Método I, p. 564. As questões referentes à parcialidade e que toda tarefa de interpretação começa por um algo já dado, também foram tratadas em um texto interessante do filósofo, Hombre y Lenguaje, publicado no segundo volume de Verdad y Método, p. 145, no qual Gadamer relata o verdadeiro enigma da linguagem, pois o pensamento sobre a linguagem não parte de uma espécie de estado de ausência de linguagem, pelo contrário, em todo saber do mundo e do próprio homem já sempre o intérprete encontra-se pego pela língua que lhe é própria (Verdad y Método p. 147). Com efeito, aprender a falar não significa utilizar um instrumento já existente para classificar o mundo já
} 
No entanto, o aspecto especulativo jamais pode ser confundido com arbitrariedade, pois a interpretação há de começar por algum dado. Como ressalta HansGeorg Gadamer, tal começo não é algo arbitrário, sequer possuindo a verdadeira característica de começo, pois qualquer texto sempre chega com um conjunto de opiniões prévias, transmitidas por dada tradição linguística, o que não se constitui em obstáculo ou impedimento para a pura compreensão, pelo contrário, esta situação dada por opiniões prévias, a partir da qual os textos são conhecidos, constitui-se o que o filósofo caracterizou como "situação hermenêutica"43.

De qualquer modo, o texto de George Orwell é indicativo de como as instâncias de poder constroem estruturas voltadas para aprisionar o homem. Prisões e desaparecimentos são grandes metáforas para representar o dogmatismo. Retirar a possibilidade do diálogo com o passado, coisificar a linguagem, transformando-a em mero instrumento do Partido, bem como criar uma imagem negativa da relação com o outro, são algumas das aproximações possíveis entre Literatura e Direito propiciadas pela obra em análise, mas que não se esgotam neste breve estudo.

\section{Conclusão.}

As relações entre Direito e Literatura são profícuas para melhor compreender o fenômeno jurídico enquanto modo de ser, de narrar a própria vida. Na obra 1984 estão explicitados os mecanismos de dominação, como o controle sobre a linguagem, não simplesmente como conjunto de sinais gráficos, mas condição de possibilidade de construção de sentido. Ser que pode ser compreendido é linguagem, como mencionava Hans-Georg Gadamer em sua famosa obra Verdad y Método traduz muito da importância do diálogo hermenêutico entre o fenômeno jurídico e as narrativas literárias.

Cotidianamente o operador do Direito é jogado para o senso comum, a instância de sentido na qual os entes jurídicos aparecem. Há uma espécie de "Novilíngua” para interpretar os textos jurídicos e os fatos do mundo da vida, para a qual devemos manter

familiar e conhecido, mas significa a aquisição da familiaridade e do conhecimento do mundo mesmo tal como vem ao encontro do homem (Verdad y Método, p. 148). De forma expressa alude: "en todo nuestro pensar e conocer, estamos ya desde siempre sostenidos por la interpretación linguística del mundo, cuya asimilación se llama crescimiento, crianza. En este sentido, el lenguaje es la verdadera huella de nuestra finitud. Simpre nos sobrepasa". 
a vigilância hermenêutica. O texto de Orwell é capaz de despertar o olhar crítico para tais processos de institucionalização do sentido, eis que sempre haverá o Ministério da Verdade, o Partido e suas teletelas.

A tradição é importante para compreender textos jurídicos, algo transmitido para o homem e na qual deverá mergulhar enquanto instância de diálogo. Que o mundo do Direito não seja como no mundo da Oceania, onde existia um órgão oficial encarregado de arbitrariamente alterar o passado, isolando o homem do seu próprio tempo. Tal questão que aparece no texto de Orwell é interessante e desperta para nunca se perder a dimensão histórica do compreender jurídico, até para não vingar o mesmo sentimento de Winston: "como quem vagueia nas florestas do fundo do mar, perdido num mundo monstruoso onde ele próprio era o monstro".

Em relação ao diálogo, a partir do horizonte de sentido do texto 1984, como eliminar as possibilidades da compreensão? Eliminando a conversação hermenêutica, na medida em que todas as respostas eram dadas pelo Grande Irmão. Nele estavam as condições de possibilidade de sentido.

Desta forma, os objetivos de uma linguagem crítica para a compreensão dos fenômenos jurídicos, ao contrário da Novilíngua, não pretende estreitar o horizonte do modo de ser dos intérpretes, mas desvelar novas possibilidades, em permanente relação com aquilo que nos chega do passado, na medida em que sempre devemos atentar para o seguinte: "Sem contato com o mundo externo e com o passado, o cidadão da Oceania é como um homem no espaço interestrelar, que não tem meios de saber que direção leva para baixo ou para cima".

Neste breve estudo, mais do que linguagem, há um manifesto pela possibilidade do diálogo com a tradição, como instrumentos da cidadania contra o arbítrio do poder totalitário. A máxima segundo a qual "quem controla o presente, controla o passado, e quem controla o passado, controla o futuro", permeia toda a obra. Ao alterar o passado, com a modificação dos registros históricos, há uma ruptura com a tradição, e a personalidade deixa de existir. A história desaparece, e um povo sem história é um povo sem cultura, sem memória. Um povo que não controla a história não constrói a sua história.

Orwell se aproxima muito de sua obra, em face da sua vivência da Espanha e na Birmânia, onde relata a sua experiência política e a sua decepção com o modelo

${ }^{43}$ GADAMER, Hans-Georg. Verdad y Método I, p. 565. 
comunista implantado na União Soviética, através do Stanilismo. Em que pese tenha lutado ao lado de trotsquistas e de anarquistas, na Guerra Civil Espanhola, esses são mais tarde perseguidos pelos stanilistas. De certo modo, isso é retratado na perseguição sofrida por Winston, que não tinha como resistir ou divergir do sistema totalitário em que se encontrava. Winston é um sujeito que tenta ser, ou seja, manter a sua consciência e a sua individualidade, mas é aniquilado pelo sistema, porque não há escapatória.

Nesse contexto de dominação, a linguagem cumpre papel fundamental. A redução da língua reduz também as possibilidades de pensamento, de posição e de opinião das pessoas. Na obra, é digna de nota a cena onde se menciona que as sucessivas edições do dicionário da "Novalíngua" eram cada vez menos extensas, em razão da progressiva eliminação das palavras. No diálogo entre Winston e o colega, no refeitório, o qual trabalhava na "Delegação da Novalíngua", ele comenta que a revolução estará completa quando a língua estiver perfeita, ao que o outro responde que o segredo é mudar da tradução ao pensamento e à reação automática.

Por isso, a atualidade da obra, que conduz ao questionamento, a respeito de quem são os nossos "Grandes Irmãos" de hoje em dia? Quem define qual a informação que deve ser liberada ao povo e como ela deve ser transmitida? O Direito, historicamente, é uma forma de controle das relações sociais. Mas, também, estabelece limites do poder exercido pelo Estado sobre a sociedade. A literatura e as demais manifestações artísticas são formas de resistência à violação dos direitos fundamentais. Os regimes totalitários, de modo geral, procuram censurar a liberdade de expressão do provo.

Daí a importância de estarmos sempre alertas e atentos, buscando a preservação de nossa história, de nossa linguagem e de nosso direito, os quais são, em última instância, os verdadeiros antídotos do totalitarismo, para que as cenas infelizes de “1984" jamais permeiem a nossa realidade.

\section{Referências.}

DWORKIN, Ronald. O Império do Direito. São Paulo: Martins Fontes, 1999.

Uma Questão de Princípio. São Paulo: Martins Fontes, 2000. 
FERNANDEZ-LARGO, Antonio Osuna. La Hermenéutica Jurídica de Hans-Georg-

Gadamer. Valladolid: Secretaria de Publicaciones, Universidad, D.L, 1992.

GADAMER, Hans-Goerg. Verdad y Método. Fundamentos de una Hermenéutica Filosófica. 5a Ed. Salamanca: Ediciones Sígueme, 1993.

HABERMAS, Jürgen. Dialética e Hermenêutica: para uma crítica da hermenêutica de Gadamer. Porto Alegre: L\& PM, 1987.

HEIDEGGER, Martin. Ser e Tempo. Parte I, 5ª Ed. Petrópolis: Vozes, 1995.

MICHELAZZO, José. Do Um como Princípio ao Dois como Unidade: Heidegger e a reconstrução ontológica do real. São Paulo: FADESP/ANNABLUMER, 1996.

OHLWEILER, Leonel. Direito Administrativo em Perspectiva. Os Termos Indeterminados à Luz da Hermenêutica. Porto Alegre: Livraria do Advogado, 2000.

ORWELL, George. 1984. 29ª ed. São Paulo: Companhia Editora Nacional, 2005.

OST, Fraçois. Contar a Lei. As Fontes do Imaginário Jurídico. São Leopoldo: Unisinos, 2004.

ROHDEN, Luiz. Hermenêutica Filosófica: entre a linguagem da experiência e a experiência da linguagem. São Leopoldo: Editora Unisinos, 2002.

SILVA, Vitor Manuel de Aguiar e. Teoria da Literatura. $8^{\text {a }}$ Ed. Coimbra: Livraria Almedina, 2006. 